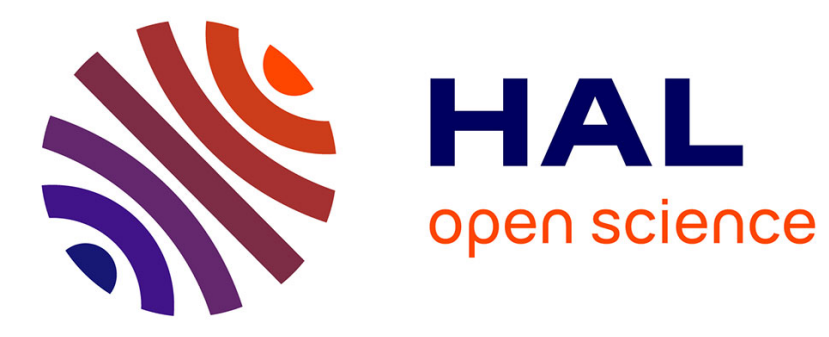

\title{
The formation and fate of internal waves in the South China Sea
}

\author{
Matthew H Alford, Thomas Peacock, Maarten C Buijsman, Luca R \\ Centurioni, Shenn-Yu Chao, Ming-Huei Chang, David M Farmer, Oliver B \\ Fringer, Ke-Hsien Fu, Patrick C Gallacher, et al.
}

\section{To cite this version:}

Matthew H Alford, Thomas Peacock, Maarten C Buijsman, Luca R Centurioni, Shenn-Yu Chao, et al.. The formation and fate of internal waves in the South China Sea. Nature, 2015, 521, pp.65 - 69. 10.1038/nature14399. hal-03208635

\section{HAL Id: hal-03208635 https://hal.science/hal-03208635}

Submitted on 11 Oct 2021

HAL is a multi-disciplinary open access archive for the deposit and dissemination of scientific research documents, whether they are published or not. The documents may come from teaching and research institutions in France or abroad, or from public or private research centers.
L'archive ouverte pluridisciplinaire HAL, est destinée au dépôt et à la diffusion de documents scientifiques de niveau recherche, publiés ou non, émanant des établissements d'enseignement et de recherche français ou étrangers, des laboratoires publics ou privés. 


\section{The formation and fate of internal waves in the South China Sea.}

Matthew H. Alford ${ }^{1}$, Thomas Peacock ${ }^{2}$, Maarten C. Buijsman ${ }^{3}$, Luca R. Centuroni ${ }^{4}$, Shenn-Yu $\mathrm{Chao}^{5}$, Ming-Huei Chang ${ }^{6}$, David M. Farmer ${ }^{7}$, Oliver B. Fringer ${ }^{8}$, Ke-Hsien Fu ${ }^{9}$, Pat Gallacher ${ }^{3}$, Hans C. Graber ${ }^{10}$, Karl R. Helfrich ${ }^{11}$, Steven Jachec ${ }^{12}$, Chris Jackson ${ }^{13}$, Jody M. Klymak ${ }^{14}$, Dong S. Ko ${ }^{3}$, Sen Jan ${ }^{6}$, T. M. Shaun Johnston ${ }^{4}$, Sonya Legg ${ }^{15}$, I-Huan Lee ${ }^{9}$, Ren-Chieh Lien ${ }^{1}$, Jennifer A. MacKinnon ${ }^{4}$, Matthieu J. Mercier ${ }^{16}$, Jim N. Moum ${ }^{1}$, Ruth Musgrave ${ }^{4}$, Jonathan D. Nash ${ }^{17}$, Theresa Paluszkiewicz ${ }^{18}$, Jae-Hun Park ${ }^{19}$, Andrew I. Pickering ${ }^{1}$, Robert Pinkel $^{4}$, Luc R. Rainville ${ }^{1}$, Steven Ramp ${ }^{20}$, Daniel R. Rudnick ${ }^{4}$, Sutanu Sarkar ${ }^{21}$, Alberto Scotti ${ }^{22}$, Harper L. Simmons ${ }^{23}$, Louis C. St. Laurent ${ }^{11}$, Karan Venayagamoorthy ${ }^{24}$, Yu-Huai Wang ${ }^{9}$, Y. J. Yang ${ }^{6}$, T. Y. Tang ${ }^{6}$

${ }^{1}$ University of Washington, Seattle, WA, USA

${ }^{2}$ Massachusetts Institute of Technology, Cambridge, MA, USA

${ }^{3}$ National Research Laboratories, Stennis Space Center, MS 39529, USA

${ }^{4}$ Scripps Institution of Oceanography, University of California San Diego, La Jolla, CA 92037, USA

${ }^{5}$ University of Maryland, Cambridge, MD 21613 USA

${ }^{6}$ Institute of Oceanography, National Taiwan University, Taipei, Taiwan

${ }^{7}$ University of Rhode Island, RI 02882, USA

${ }^{8}$ Stanford University, Palo Alto, CA 94305, USA

${ }^{9}$ National Sun-Yat Sen University, Kaohsiung, Taiwan

${ }^{10}$ University of Miami, Miami, FL 33149, USA 
${ }^{11}$ Woods Hole Oceanographic Institution, Falmouth, MA 02543, USA

${ }^{12}$ Florida Institute of Technology, Melbourne, FL 32901, USA

${ }^{13}$ Global Ocean Associates, Alexandria, VA 22310, USA

${ }^{14}$ University of Victoria, Victoria, BC V8W 3P6, Canada

${ }^{15}$ Princeton University, NJ 08542, USA

${ }^{16}$ Institut de Mécanique des Fluides de Toulouse, Toulouse, France

${ }^{17}$ Oregon State University, Corvallis, OR, USA

${ }^{18}$ Office of Naval Research, Arlington, VA, USA

${ }^{19}$ Korea Institute of Ocean Science and Technology, Ansan, Korea

${ }^{20}$ Soliton Research Inc., Monterey, CA 93924, USA

${ }^{21}$ University of California San Diego, La Jolla, CA 92037, USA

${ }^{22}$ University of North Carolina, Chapel Hill, NC 25599, USA

${ }^{23}$ University of Alaska at Fairbanks, Fairbanks, AK 99775, USA

${ }^{24}$ Colorado State University, Fort Collins, CO 80523, USA

The oceans' most powerful known internal waves - propagating disturbances of the background density stratification - are generated in the Luzon Strait, between the Pacific Ocean and the South China Sea. Locally, these waves impact marine life and ocean engineering, and globally they influence large-scale ocean circulation patterns. Despite over a decade of study, a complete cradle-to-grave picture, with field data validating modeling of each stage of the process - from generation, through propagation to dissipation - has been lacking. In particular, confusion has persisted regarding the generation mechanism and there has 
been no validation of predicted energy budgets due to the lack of in-situ data from the Luzon Strait, where extreme flow conditions make measurements challenging. Here we present the results of the IWISE program that sets a new standard in coordinating internal wave field experiments with modeling. These results elucidate the generation mechanism due to the interaction of complex topography with mixed barotropic tides, provide evidence of dramatic overturns and intense dissipation within the Luzon Strait, and reveal the impact of the Kuroshio western boundary current. Building on the results of previous field studies, the IWISE results enable us to provide the first validated and comprehensive energy budget for internal waves across the South China Sea.

Internal waves, the subsurface analogue of the familiar surface gravity waves that break on beaches, are propagating disturbances of the ocean's density stratification. Generated primarily by tidal flow past seafloor topography and forcing by surface winds, and typically having multikilometer-scale horizontal wavelengths, their estimated 1TW of internal wave energy flux is understood to play a crucial role in the ocean's global redistribution of heat and momentum [1]. A major challenge is to improve understanding of internal wave generation, propagation, steepening and dissipation, so that these processes can be more accurately incorporated in climate models.

The internal waves that originate from the Luzon Strait on the eastern margin of the South China Sea (SCS) are the largest yet documented in the global oceans (Figure 1). As the waves propagate west from the Luzon Strait they steepen dramatically (Figure 1a), producing distinctive solitary wave fronts evident in sun glint and synthetic aperture radar (SAR) images from satellites 
(Figure 1b). When they shoal onto the continental slope to the west, the downward displacement of the ocean's layers associated with these solitary waves can exceed $250 \mathrm{~m}$ in 5 minutes [2]. On such a scale, these waves pose hazards for underwater navigation and offshore drilling, and raise nutrients from the deep ocean that nourish coral reefs [3] and pilot whale populations that forage in their wakes [4].

Over the past decade there have been a number of field studies conducted in the region and this work has been comprehensively reviewed [5, 6]. All of these studies, however, focused on the propagation of the internal waves across the SCS and their interactions with the continental shelf of China. Until the present study there had been no substantial in situ data gathered at the generation site of the Luzon Strait, in large part because of the extremely challenging operating conditions. A direct consequence has been persistent confusion regarding the true nature of the generation mechanism [6], no data to test numerical predictions of energy budgets [7], and limited understanding of the impact of the Kuroshio on the emergence of internal solitary waves [6].

The goal of IWISE is to obtain the first comprehensive in situ data set from the Luzon Strait to support a validated, cradle-to-grave picture of the life cycle of the world's largest oceanic internal waves (see Methods section for extensive details). IWISE is the most substantial internal wave field program since the Hawaiian Ocean Mixing Experiment (HOME) revealed the ability of deep ocean ridge systems to generate globally important internal wave fields and associated near field turbulence [8]; IWISE is significantly broader in scope than HOME, however, as it also encompasses the evolution and fate of the radiated internal tide. A short pilot program was performed 
in the summer of 2010 to determine the feasibility of operating at desired locations [9], and the full field program was executed throughout the summer of 2011. This Letter is a synthesis of the results from both programs.

The internal waves in the SCS derive their energy from the barotropic (i.e. surface) tide, the flow arising from astronomical forcing of the oceans by the sun and the moon. The barotropic tides in this region are a combination of twice-daily (semidiurnal, D2) and once-daily (diurnal, D1) motions, giving rise to a strong diurnal inequality and a fortnightly amplitude envelope due to the interaction of lunar and solar tides (Figure 1d). Our moorings and autonomous gliders operating within and to the west of the Luzon Strait, respectively, reveal time-averaged westward energy fluxes as high as $74 \pm ? ? \mathrm{~kW} \mathrm{~m}^{-1}$ (Figure 2a), over 100 times typical open-ocean values [10] and exceeding all other known generation sites around the world [9]. Both the magnitude and directionality of the measured fluxes are consistent with the predictions of our high-resolution, near-field, three-dimensional numerical model (see Methods), as well as previous numerical predictions [7].

There is a clockwise feature of the total energy flux pattern in the northern section of the Luzon Strait, between the tall east and west ridges (Figure 2a). This feature exists because the double-ridge structure creates a $100 \mathrm{~km}$-scale resonant cavity for the $\sim 100 \mathrm{~km}$ wavelength semidiurnal internal tide [11], and is further confirmed by observations of very high energy density but very little energy flux between the two ridges that is characteristic of a standing wave pattern [9]. As tidal flow transits the ridge in the vicinity of the Batanes Islands (Figure 2f) there are dramatic localized lee wave phenomena. Two diurnal cycles of shipboard time series of velocity and density, 
obtained at the location of the dashed lines in Figures $2 \mathrm{~b}$ and $2 \mathrm{c}$, are presented in Figure $2 \mathrm{~d}$. Observed vertical displacements of the ocean layers reach up to 500m and the associated depthintegrated turbulent dissipation levels (Figure 2e, see methods) approach $20 \mathrm{~W} \mathrm{~m}^{-2}$, exceeding open ocean values by a factor of 1,000-10,000 $[9,12]$. The intrusion of the Kuroshio into the Luzon Strait was also clearly discerned (Figure 4c).

There was no evidence of significant nonlinear internal waves preceding $120.5^{\circ} \mathrm{E}$, laying to rest a widely stated conjecture that the large amplitude internal solitary waves arise via a lee wave mechanism. Rather, what emerges immediately to the west of the Luzon Strait is a broad, energetic and spatially coherent internal tide (Figure 1a, 2a and 3a,b) at a combination of semidiurnal and diurnal frequencies (Figure 1d). The structure of the wave field is dominated by so-called mode-1 behavior [9], this being the fundamental vertical mode of oscillation in which velocity in the upper few hundred meters of the ocean is in the opposite direction to, and oscillates out of phase with, that in the deeper ocean (Figure 3c). The three-dimensional structure of the ridge system within the Luzon Strait shapes the radiated semidiurnal and diurnal internal tides somewhat differently. Semidiurnal internal tide energy flux is strongest within a beam that emanates from the central section of the Luzon Strait, between $20^{\circ}-21^{\circ} \mathrm{N}$ (Figure 3a), while a somewhat broader beam of diurnal energy flux emanates from across the central and southern sections of the Luzon Strait. The existence of these beams is validated by the field data: characteristic diurnal energy fluxes of $\sim 5 \mathrm{~kW} / \mathrm{m}$ and $\sim 20 \mathrm{~kW} / \mathrm{m}$ were detected in the central and southern sections of the Luzon Strait, respectively; conversely, for the semi-diurnal energy flux these values were $\sim 20 \mathrm{~kW} / \mathrm{m}$ and $\sim 10 \mathrm{~kW} / \mathrm{m}$ in the central and southern sections, respectively [9]. 
The combination of mode- 1 dominated semidiurnal and diurnal internal tides sets the initial condition for the evolution of large amplitude solitary waves [13]. Whether or not steepening occurs depends crucially on the balance between nonlinearity and rotational dispersion, which serve to enhance and reduce the steepness of the wavefronts, respectively $[14,15]$. When the semidiurnal internal tide dominates, nonlinearity can overcome rotational dispersion leading to the formation of internal solitary waves; if diurnal forcing dominates, however, rotational dispersion tends to suppress formation. Other factors are the fortnightly spring-neap cycle (Figure 1d), which sets the overall amplitude of barotropic tidal forcing in the Luzon Strait, and the interaction of the semidiurnal and diurnal tides, which can cause alternating strong and weak wave fronts [13].

A widespread belief has been that large amplitude internal solitary waves are not prevalent in the South China Sea throughout winter. We did not find this to be the case, however, as PIES located in the deep basin clearly observed solitary waves to persist throughout the winter of 2010-2011 [16] (Figure 4b). The explanation for the absence of solitary waves in previous observations is that wind conditions tend to obscure the remotely sensed surface signature of the solitary waves during winter, and in the case of the previous mooring observations [17] (Figure 4a) refraction associated with the Kuroshio intrusion across the Luzon Strait directed the principal beam of semidiurnal internal tide energy, and thus the solitary waves, to the south of where measurements were being made [16] (Figure 4c).

Proceeding into the shallower waters of the Dongsha Plateau at speeds of roughly $3 \mathrm{~m} \mathrm{~s}^{-1}$, 
the internal solitary waves begin to slow down. Eventually, the wave-induced fluid velocities can exceed the wave speed leading to the formation of trapped cores [18], wherein fluid is carried along with the wave. At this stage, vertical water displacements due to the waves reach up to around 170 $\mathrm{m}$, nearly $40 \%$ of the local ocean depth, in only a few minutes and have wavelengths of only a few hundred meters (Figure 4c). The solitary waves become highly turbulent, leading to strong vertical mixing that has been postulated to contribute to the high biological productivity in the vicinity of the nearby Dongsha coral atoll [3]. We observed the waves to become convectively unstable, producing vertical overturns of up to one hundred meters within the core. The gradient Richardson number was also determined to fall below 0.11 , which also allows for the growth of shear-driven instability via Kelvin-Helmholtz billows. Estimated turbulent dissipation rates are extreme, exceeding $1.5 \times 10^{-4} \mathrm{Wkg}^{-1}$ and contributing to an integrated dissipation level of 10 $\mathrm{kWm}^{-1}$; this dissipation rate is of comparable magnitude to those observed in coastal oceans, but here occurring in depths of $1000 \mathrm{~m}$.

The comprehensive IWISE field measurements enable us to provide the first reasonable and validated estimate of an energy budget for internal waves throughout the entire South China Sea, as summarized in Figure 3c. Out of a total conversion of $31 \pm 3 \mathrm{GW}$ from the barotropic (i.e. surface) tide at the Luzon Strait, $19 \pm 2 \mathrm{GW}$ is radiated to the east and west, implying about $12 \mathrm{GW}$ $(38 \pm 10 \%)$ of nearfield turbulent dissipation by wave breaking. This inferred dissipated fraction is over twice the $15 \%$ estimated to be locally dissipated at the Hawaiian Ridge [19]. The westward energy flux at $120^{\circ} \mathrm{E}$ is approximately equipartitioned between semidiurnal and diurnal motions, with no energy yet in the sharp wavefronts. Closer to the continental slope at $117.25^{\circ} \mathrm{E}$, however, 
the nonlinear internal waves (NLIW) gain energy at the expense of the internal tide, and energy is equipartitioned among all three components (D1, D2 and NLIW). At the continental slope, the diurnal motions are partially reflected (eastward arrows at $118.25^{\circ} \mathrm{E}$ ), while the steeper semidiurnal motions and nonlinear waves are transmitted [20]. By $115.19^{\circ} \mathrm{E}$, nearly all energy in the nonlinear waves and internal tides has dissipated.

The arrival time of solitary waves in the western SCS can now be reliably predicted within an accuracy of 1-2 hours, given knowledge of the barotropic tidal currents at Luzon Strait and the time-variable Kuroshio. The wave amplitude is not yet as predictable, however, owing to its sensitivity to weakly nonlinear and nonhydrostatic mechanisms that are not well captured by stateof-the-art computational models. And because dissipation in the generation region should scale as the wave-induced velocity cubed [21], some uncertainty remains regarding the time variability of the locally dissipated fraction of barotropic-to-baroclinic conversion. Overall, the results of the IWISE program have substantially advanced current understanding and set a new standard in coordinated field studies and modeling of internal waves. 


\section{Methods}

Numerical models Several numerical models were used in this paper, representing varying balances between resolution, domain size and resolved processes. Four 3D models with realistic bathymetry and stratification (a "farfield," a "nearfield" and two "Kuroshio" models), and an ultrahigh-resolution 2D model.

The 3D models were used to simulate basin-scale waves, near-field physical processes, and the role of the Kuroshio, respectively. All were forced with predictions using 8 tidal constituents (K1, O1, P1, Q1, K2, M2, N2 and S2) from a barotropic tidal model, TPXO7.2 [22], which was validated against measured currents in the region in this and a previous experiment $[9,17]$. Bathymetry was from multibeam depth soundings where available, and from the 30 arc-second [23] database elsewhere. Stratification was horizontally uniform in the farfield and nearfield models, obtained from the generalized digital environmental model database (GDEM) climatology for the month of August [24] for the farfield model and from August 2010 field data for the near field model. Stratification in the Kuroshio models was from larger-scale data-assimilating regional simulations.

The "farfield" model (Figures 1(a), 3(a) and 3(b)) is based on the Hallberg isopycnal model and encompasses the entire South China Sea with a spatial resolution of $2 \mathrm{~km}$ and a 40 layers in the vertical [25]. The "near-field" model data (Figure 2a), with a spatial resolution of 250m, were generated using a 154-layer implementation of the MITgcm model, based on the configuration in [11]. The MITgcm model was also used to generate the ultra-high-resolution, two-dimensional numerical results presented in figures 2(b) and 2(c). For this, the bathymetry was a transect taken from the 
"near-field" model and calculations were performed using a telescoped grid with horizontal and vertical resolutions of $7.8 \mathrm{~m}$ and $6.1 \mathrm{~m}$, respectively.

The two Kuroshio models used are different implementations, but similar in their resolution, intent and skill. One (Figure 4a, vectors) is an application of the NRL Ocean Nowcast /Forecast System [26-28], an integration of a dynamical ocean model (HYCOM) and a statistical dataanalysis model. In addition to the tidal forcing, the model's open boundary conditions are from a larger scale model for the entire East Asian seas [29]. The second, used to generate the ray paths (Figure 4c, red/blue meshes) is from HYCOM, a data-assimilating version of the Princeton Ocean model [30].

Shipboard measurements The basic physical quantities required to characterize physical ocean flows are the potential density (density with the compression effects of hydrostatic pressure removed) and velocity. The former is measured with CTDs (conductivity temperature depth instruments) that are repeatedly lowered and raised from a shipboard winch. Salinity (S) is computed from temperature $(\mathrm{T})$, conductivity and pressure $(\mathrm{P})$ measurements, and density is then a function of salinity, temperature and pressure. Velocity is measured with ADCPs (acoustic Doppler current profilers). Affixed to the hull of the ship or lowered with the CTD instrument, velocity is measured as a function of depth beneath the ship by the phase shift of $75-\mathrm{KHz}$ acoustic pulses backscattered from the water column. The energy flux measurements presented in Figure 2a (flux calculation described next) are computed from 36-hour stations wherein velocity and pressure are repeatedly measured by cycling the CTD up and down approximately once each hour. The measurements in Figure 2e are from a specialized "fast CTD" system designed to sample much faster than a con- 
ventional CTD (a profile every approximately ten minutes as opposed to about an hour, depending on water depth).

Glider measurements The first measurements of energy flux were made from autonomous gliders as part of IWISE. Gliders are autonomous underwater vehicles that move up and down through the water by adjusting their buoyancy which is accomplished by filling and draining oil from a bladder. Wings allow the glider to "fly" through the water at about $25 \mathrm{~cm} / \mathrm{s}$. During IWISE, two gliders were deployed for about two months each, and sampled density and velocity in the upper $500 \mathrm{~m}$ each 3 hours.

Moored measurements Three types of moored measurements were made during IWISE. Profiling moorings featuring a McLane Moored Profiler (MP) crawling up and down a vertical moored wire approximately each 1.5 hour between $300-400 \mathrm{~m}$ and $\approx 10 \mathrm{~m}$ above the bottom. Above, a series of $\approx 30$ densely-spaced temperature loggers and an ADCP gave temperature (from which density was computed) and velocity in the upper ocean. The MPs carried current meters and CTDs, giving continuous, full-water-column measurements of density and velocity from a mooring, a challenging task.

ADCP/T-chain moorings had only ADCPs and temperature and/or salinity measurements, giving faster sampling at the cost of continuous data. Both of these types of moorings were prone to significant knockdowns by the extreme currents in Luzon Strait. Knockdowns were minimized by highly taut designs and (for one mooring) a low-drag cylindrical float. When they occurred (up to $100 \mathrm{~m}$ in the worst case), they were corrected for by means of pressure measurements on the top 
subsurface floats.

A final moored measurement was bottom-mounted Pressure Inverted Echo Sounders (PIES), which measure bottom pressure and the round-trip bottom-top-bottom travel time of an acoustic pulse transmitted upward every few seconds. Since sound speed depends on temperature, these signals are proportional to the mode- 1 displacement of the thermocline [31]. True mode- 1 displacements in Figures 4(a) and (b) were computed from travel time using nearby moored in-situ temperature measurements, and have an overall uncertainty of $4 \mathrm{~m} \mathrm{[31].}$

Turbulence measurements The turbulence measurements in Figure 4(c) were obtained directly using a Vertical Microstructure Profiler (VMP). The turbulent dissipation rate, $\epsilon$, was estimated by fitting small-scale velocity shear observations to a theoretical spectrum and integrating following [32]. The turbulent dissipation results in Figure 2 were obtained indirectly using the method of overturns or "Thorpe sorting" [33], which computes the outer scale of the turbulence via the vertical distance parcels of water have moved from a stably stratified profile. The method has been demonstrated in numerous previous studies to give average profiles within a factor of two of direct measurements.

Synthetic Aperture Radar (SAR) imagery. Although nonlinear internal waves propagate in the interior of the ocean, their currents produce convergent (rough) and divergent (smooth) zones on the ocean surface that move in phase with their subsurface crests and troughs. These variations in surface roughness create the distinctive light/dark pattern of the internal wave packets found in synthetic aperture radar images of the ocean (Figure 1b), which have typical horizontal resolution 
of tens of meters. The technique is sensitive to the background roughness of the sea surface, which depends on wind speed and other factors. Therefore, imagery is an excellent indicator of the location and morphology of the wave fronts, but generally cannot give wave amplitude.

Energy flux Internal tide energy flux (presented in Figures 2(a) and 3) is computed from both model and observed data as the depth integral of $\left\langle\mathbf{u}^{\prime} p^{\prime}\right\rangle$, where $\mathbf{u}^{\prime}$ is the measured velocity fluctuation and $p^{\prime}$ is the baroclinic pressure, computed from density assuming hydrostatic balance according to the method of [34].

Energy flux is computed separately for the semidiurnal and diurnal motions by use of harmonic analysis. Shipboard stations are always $\geq 36$ hours, allowing separation of these motions from each other and from the inertial frequency, which is 33.4 hours at this latitude. For each 36-hour station or 3-day time period in the case of moored and glider data, least-square fits are done at each depth to semidiurnal, diurnal and inertial motions. Much longer time series $(\sim 14$ days) would be required to separate the different tidal constituents within each band (e.g. M2/S2 and $\mathrm{K} 1 / \mathrm{O} 1$ ), so the diurnal and semidiurnal motions are referred to as D1 and D2, respectively.

Nonlinear coupling between different frequencies would complicate our method of separation into bands. To ensure that nonlinear terms are not important in this context, the sum of the separated fluxes is compared to the total flux prior to separation. The two agree to within $10 \%[9,35]$.

Because it requires a vertical integral, the calculation of $p^{\prime}$ relies on full-water-column data. Therefore, gaps in the water column measurements give rise to errors, particularly when they 
are near the surface where the flux is the greatest. For the model data and CTD/ADCP station measurements (Figure 2a) gaps and associated errors are negligible. For the moored measurements where gaps are only tens of meters out of thousands, the associated errors are about $10 \%$, which are determined by sampling the full-water-column model output with the coverage of the moorings. For the glider measurements which sample only the upper $500 \mathrm{~m}$, calculation of energy flux relies on fitting the data to the first baroclinic mode. Because the moored data verify that the bulk of the energy is in this mode, this is an excellent assumption, giving glider uncertainty in flux of about $25 \%[36]$.

Energy flux of nonlinear waves (presented in Figure 3) has two additional terms in addition to the linear term computed above for the internal tides. An accurate expression for the energy flux of nonlinear waves is $c E$, where $c$ is the wave speed and $E$ is the sum of their kinetic and available potential energy [37]. The nonlinear waves' short timescales (minutes as opposed to hours for the internal tides) enables them to be easily isolated from the internal tides by means of bandpass filtering.

Energy Budget Calculation While in general internal wave energy arises from a combination of wind and tidal forcing, in Luzon Strait the dominant energy source for the internal tides is the barotropic tide. Conversion to baroclinic energy can be quantified as $C=U_{B T} \cdot \nabla H p_{b o t}$. In steady state, an energy budget for the internal tides can be written as

$$
C-\nabla \cdot F=D
$$


where $D$ represents all processes removing energy from the internal tide including dissipation and transfer of energy to the sharp nonlinear waves seen to the west. In the near field region where no nonlinear waves are yet present, $D$ represents primarily turbulent processes. In the west, reductions in internal tide flux also arise as nonlinear wave fluxes increase (Figure 3).

Because even our intensive nearfield observations are far too sparse, we evaluate the nearfield energy budget using the model, first validating the model fluxes, conversion and dissipation at the observational sites. The near field model does not resolve turbulence, but does resolve the processes that lead to them, primarily breaking lee waves as shown in Figure 2. Model dissipation is computed from a closure scheme developed by [38] similar to the above Thorpe sorting algorithm used in the measurements. A point-by-point comparison of observed and modeled energy flux and conversion shows that model and observed values are generally within a factor of two of each other with no detectable bias, with flux direction agreeing within $20-30^{\circ}$. Observed and measured dissipation have also been demonstrated to be within a factor of two of one another in breaking lee waves observed at another site [39], though a detailed comparison at Luzon Strait is not yet complete.

Internal tide and nonlinear internal wave flux estimates further to the west in Figure 3 are from moorings. Turbulence estimates on the continental slope and upper shelf are from Thorpe scales, while those west of $117.25^{\circ} \mathrm{E}$ are directly measured with the VMP. The separate eastward and westward fluxes from the mooring at $118.25^{\circ} \mathrm{E}$ are estimated by assuming the continental slope is a vertical wall (a good assumption for the shallow diurnal motions); then, the separate fluxes are estimated from the ratio of the total energy to the flux with knowledge of the distance between the 
mooring and the wall.

Integrated dissipation on the slope and shelf is computed from the available observations by simply integrating in depth and multiplication by the areas indicated in Figure 3c, which assumes that the observed locations are representative. Because the validity of this assumption is not known, the estimates are uncertain.

1. Ferrari, R. \& Wunsch, C. Ocean circulation kinetic energy: Reservoirs, sources, and sinks. Annual Review of Fluid Mechanics 41, 253-282 (2009).

2. Ramp, S. R. et al. Internal solitons in the northeastern South China Sea, part I: sources and deep water propagation. IEEE J. of Oceanic Engr. 29, 1157-1181 (2004).

3. Wang, Y. H., Dai, C. F. \& Chen, Y. Y. Physical and ecological processes of internal waves on an isolated reef ecosystem in the South China Sea. Geophys. Res. Lett. 34 (2007).

4. Moore, S. \& Lien, R.-C. Pilot whales follow internal solitary waves in the South China Sea. Marine Mammal Science 23, 193-196 (2007).

5. Cai, S., Xie, J. \& He, J. An Overview of Internal Solitary Waves in the South China Sea. Surv. Geophys. 33, 927-943 (2012).

6. Guo, C. \& Chen, X. A review of internal solitary wave dynamics in the northern South China Sea. Progress in Oceanography 121, 7-23 (2014).

7. Jan, S., Lien, R. \& Ting, C. Numerical study of baroclinic tides in Luzon Strait. Journal of Oceanography 64, 789-802 (2008). 
8. Rudnick, D. et al. From tides to mixing along the Hawaiian Ridge. Science 301, 355-357 (2003).

9. Alford, M. H. et al. Energy flux and dissipation in Luzon Strait: Two tales of two ridges. $J$. Phys. Oceanogr. 41, 2211-2222 (2011).

10. Alford, M. H. Energy available for ocean mixing redistributed through long-range propagation of internal waves. Nature 423, 159-163 (2003).

11. Buijsman, M. et al. Three-Dimensional Double-Ridge Internal Tide Resonance in Luzon Strait. J. Phys. Oceanogr. 44, 850-869 (2014).

12. Pinkel, R., Buijsman, M. \& Klymak, J. M. Breaking topographic lee waves in a tidal channel in luzon strait. Oceanography 25, 160-165 (2012).

13. Li, Q. \& Farmer, D. The generation and evolution of nonlinear internal waves in the deep basin of the South China Sea. Journal of Physical Oceanography 41, 1345-1363 (2011).

14. Helfrich, K. R. \& Grimshaw, R. H. J. Nonlinear disintegration of the internal tide. J. Phys. Oceanogr. 38, 686-701 (2008).

15. Farmer, D., Li, Q. \& Jae-Hun Park. Internal wave observations in the South China Sea: the role of rotation and nonlinearity. Atmos.-Ocean. 47, 267-280 (2009).

16. Park, J.-H. \& Farmer, D. M. Effects of Kuroshio intrusions on nonlinear internal waves in the South China Sea during winter. J. Geophys. Res. in press (2014). 
17. Ramp, S. R., Yang, Y. \& Bahr, F. L. Characterizing the nonlinear internal wave climate in the Northeastern South China Sea. Nonlinear Processes in Geophysics 17, 481-498 (2010).

18. Lien, R.-C., Henyey, F., Ma, B. \& Yang, Y.-J. Large-amplitude internal solitary waves observed in the northern South China Sea: Properties and energetics. J. Phys. Oceanogr. 44, 1095-1115 (2014).

19. Klymak, J. M. et al. An estimate of tidal energy lost to turbulence at the Hawaiian Ridge. $J$. Phys. Oceanogr. 36, 1148-1164 (2006).

20. Klymak, J. M., Alford, M. H., Pinkel, R., Lien, R. C. \& Yang, Y. J. The breaking and scattering of the internal tide on a continental slope. J. Phys. Oceanogr. 41, 926-945 (2011).

21. Klymak, J. M., Pinkel, R. \& Rainville, L. Direct breaking of the internal tide near topography: Kaena Ridge, Hawaii. J. Phys. Oceanogr. 38, 380-399 (2008).

22. Egbert, G. \& Erofeeva, S. Efficient inverse modeling of barotropic ocean tides. J. Atmos. Ocean. Tech. 19, 183-204 (2002).

23. Smith, W. H. F. \& Sandwell, D. T. Global sea floor topography from satellite altimetry and ship depth soundings. Science 277, 1957-1962 (1997).

24. Teague, W. J., Carron, M. J. \& Hogan, P. J. A comparison between the generalized Digital Environmental Model and Levitus climatologies. J. Geophys. Res. 95, 7167 - 7183 (1990).

25. Simmons, H., Jayne, S., Laurent, L. S. \& Weaver, A. Tidally driven mixing in a numerical model of the ocean general circulation. Ocean Model. 82, 245-263 (2004). 
26. Ko, D. S., Martin, P. J., Rowley, C. D. \& Preller, R. H. A real-time coastal ocean prediction experiment for mrea04. Journal of Marine Systems 69, 17-28 (2008).

27. Chen, Y.-J., Shan Ko, D. \& Shaw, P.-T. The generation and propagation of internal solitary waves in the south china sea. Journal of Geophysical Research: Oceans 118, 6578-6589 (2013).

28. Ma, B. B., Lien, R.-C. \& Ko, D. S. The variability of internal tides in the Northern South China Sea. Journal of oceanography 69, 619-630 (2013).

29. Ko, D. S., Chao, S.-Y., Huang, P. \& Lin, S. F. Anomalous Upwelling in Nan Wan: July 2008. Terrestrial, Atmospheric \& Oceanic Sciences 20 (2009).

30. Chassignet, E. P. et al. The HYCOM (HYbrid Coordinate Ocean Model) data assimilative system. J. Mar. Syst. 65, 60-83 (2007).

31. Li, Q., Farmer, D. M., Duda, T. F. \& Ramp, S. Acoustical measurement of nonlinear internal waves using the inverted echo sounder. J. Atmos. Ocean. Tech. 26, 2228-2242 (2009).

32. Gregg, M. C. Estimation and geography of diapycnal mixing in the stratified ocean. In Imberger, J. (ed.) Physical Processes in Lakes and Oceans, vol. 54, 305-338 (American Geophysical Union, Washington, D.C., 1998).

33. Dillon, T. M. Vertical overturns: A comparison of Thorpe and Ozmidov length scales. $J$. Geophys. Res. 87, 9601-9613 (1982). 
34. Althaus, A., Kunze, E. \& Sanford, T. Internal tide radiation from Mendocino Escarpment. $J$. Phys. Oceanogr. 33, 1510-1527 (2003).

35. Pickering, A. I., Alford, M. H., Rainville, L., Nash, J. D. \& Lim, B. Spatial and temporal variability of internal tides in Luzon Strait. J. Phys. Oceanogr. in preparation (2014).

36. Johnston, T. M. S., Rudnick, D. L., Alford, M. H., Pickering, A. I. \& Simmons, H. L. Internal tidal energy fluxes in the South China Sea from density and velocity measurements by gliders. J. Geophys. Res. 118, 10.1002/jgrc.20311 (2013).

37. Moum, J. N., Klymak, J. M., Nash, J. D., Perlin, A. \& Smyth, W. D. Energy transport by nonlinear internal waves. J. Phys. Oceanogr. 37, 1968-1988 (2007).

38. Klymak, J. M. \& Legg, S. M. A simple mixing scheme for models that resolve breaking internal waves. Ocean Modell. 33, 224 - 234 (2010).

39. Alford, M. H., Klymak, J. M. \& Carter, G. S. Breaking internal lee waves at Kaena Ridge, Hawaii. Geophys. Res. Lett. 41, 906-912 (2014).

40. Chang, M.-H., Lien, R.-C., Tang, T.-Y., D’Asaro, E. \& Yang, Y.-J. Energy flux of nonlinear internal waves in northern South China Sea. Geophys. Res. Lett. 33, doi:10.1029/2005GL025196 (2006).

41. St. Laurent, L. C., Simmons, H. L., Tang, T. Y. \& Wang, Y. H. Turbulent properties of internal waves in the South China Sea. Oceanography 24, 78-87 (2011). 
Acknowledgements This article is dedicated to T-Y Tang. Our work was supported by the U.S. Office of Naval Research and the Taiwan National Science Council. We are indebted to the crew of all of the research vessels that supported this work, as well as to the technical staff of the seagoing institutions. Without the skill and hard work of all of these people, these observations would not have been possible.

Competing Interests The authors declare that they have no competing financial interests.

Correspondence Correspondence and requests for materials should be addressed to Matthew Alford (email: malford@ucsd.edu). 
Figure 1 Overview of internal waves in the South China Sea. (a) Displacement of the pycnocline (the sharp density transition layer $\sim 200 \mathrm{~m}$ below the surface) using data from the far field numerical simulation. (b) A collage of several Synthetic Aperture Radar (SAR) images. Wave fronts are visible because they focus surface waves, increasing the sea surface roughness. (c) Autonomous, moored and shipboard instrumentation deployed during IWISE. The Kuroshio is sketched schematically. (d) Time series of depth-averaged tidal current in Luzon Strait over a spring/neap cycle, showing the presence of once-daily (diurnal, D1) and twice-daily (semidiurnal, D2) frequencies.

Figure 2 Near-field processes in the Luzon Strait. (a) Time-mean total energy flux from the near field numerical model (gray arrows) and different field measurement techniques (colored arrows). (b,c) Two-dimensional model snapshots showing internal wave dynamics at the location indicated in (a), corresponding to time instances $T_{0}$ and $T_{1}$ indicated in figure (f). Colors and lines in (b) and (c) indicate east-west velocity and density contours, respectively. (d) The corresponding field measurements at the location indicated by the vertical dashed line in $(b, c)$. (e) Depth-averaged dissipation rate computed from Thorpe scales. (f) Depth-integrated eastward tidal transport, showing the times $T_{0}, T_{1}$ of the frames in $(b, c)$.

Figure 3 Internal wave energy fluxes for the South China Sea. (a) Semidiurnal and (b) diurnal energy flux from the far-field model. (c) Cross section of SCS bathymetry across $21^{\circ} \mathrm{N}$. The processes of generation, breaking, propagation, steepening and dissipation 
are shown schematically. Arrows atop the graphic indicate energy fluxes at $21^{\circ} \mathrm{N}$ in the semidiurnal, diurnal internal tides and in the solitary or nonlinear internal waves (NLIW). Flux values at $120^{\circ} \mathrm{E}$ are from the near-field model; values at $115.19^{\circ} \mathrm{E}, 117.25^{\circ} \mathrm{E}$ and $118.25^{\circ} \mathrm{E}$ are from observations [20,40]; dissipation values are from [41] and [20]. About $1.5 \mathrm{~kW} \mathrm{~m}^{-1}$ of the diurnal energy reflects back eastward at the continental slope [20].

Figure 4 The Kuroshio and its impact on wave propagation. (a) Observed (green) and modeled Kuroshio flow during June-August 2011 (gray) in the Luzon Strait region. Red and blue meshes are modeled phase lines of internal waves during Feb 2006 (red) and Feb 2011 (blue). (b,c) Measured wave displacement at the locations shown. Waves were observed year-round at the southern station in 2011 (c), but not at the northern station (b) in 2006, when the Kuroshio deflected the internal wave paths southward (a, red). 

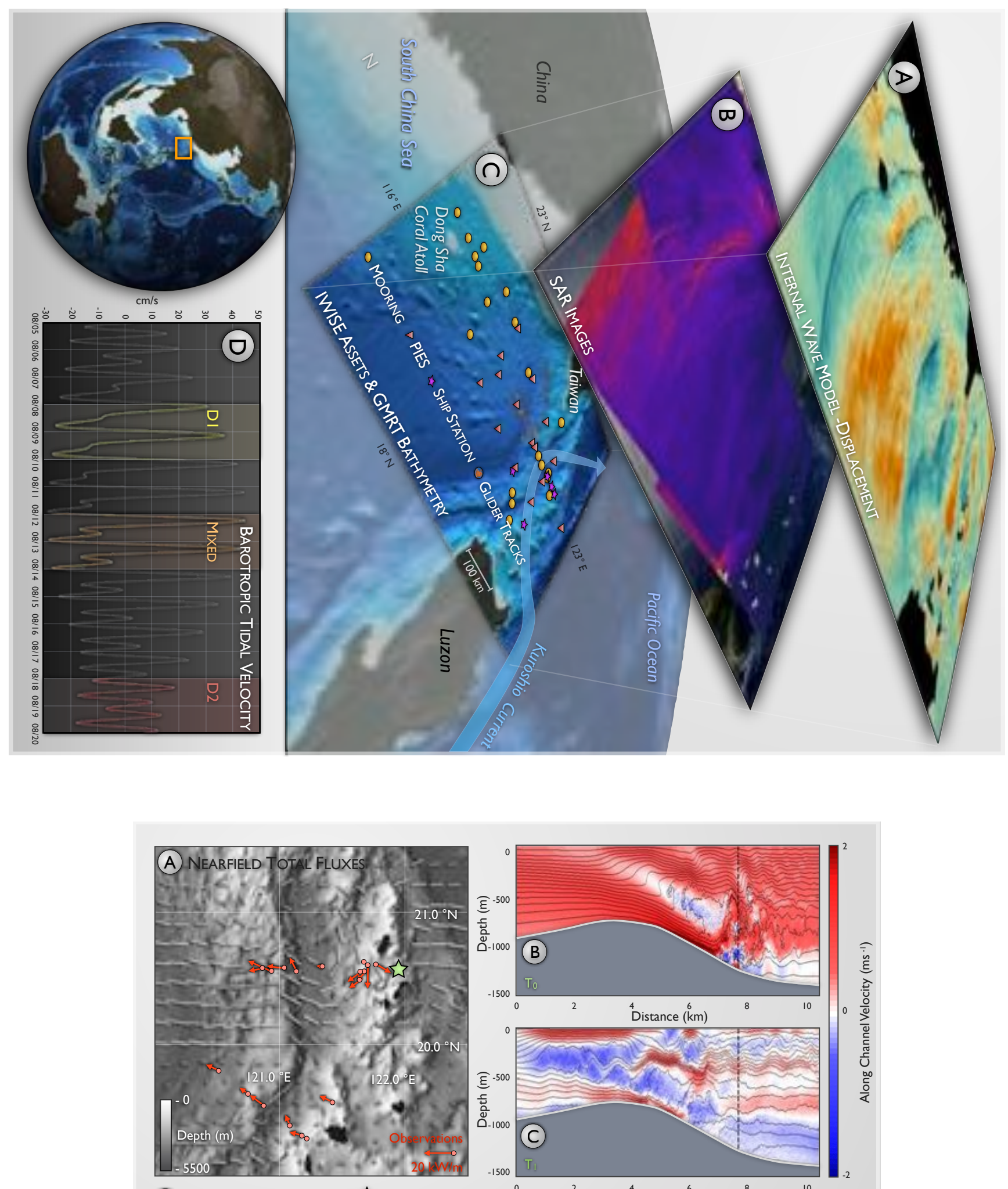

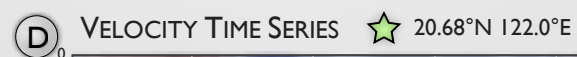

$+\frac{1}{2}$

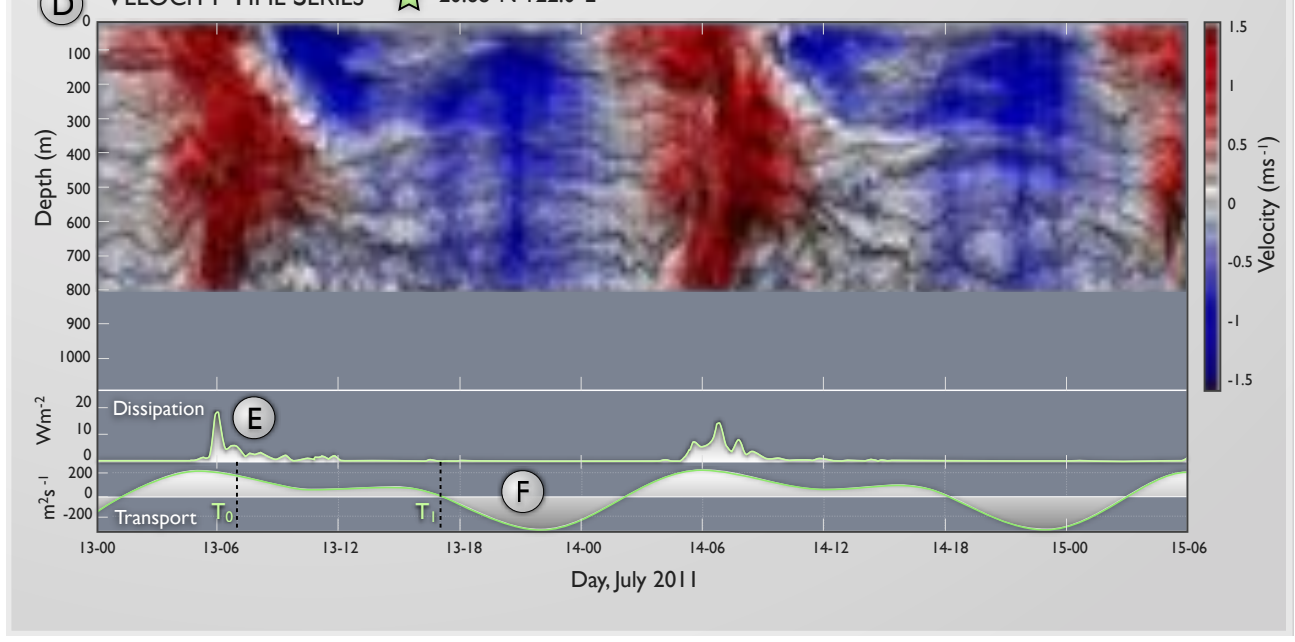



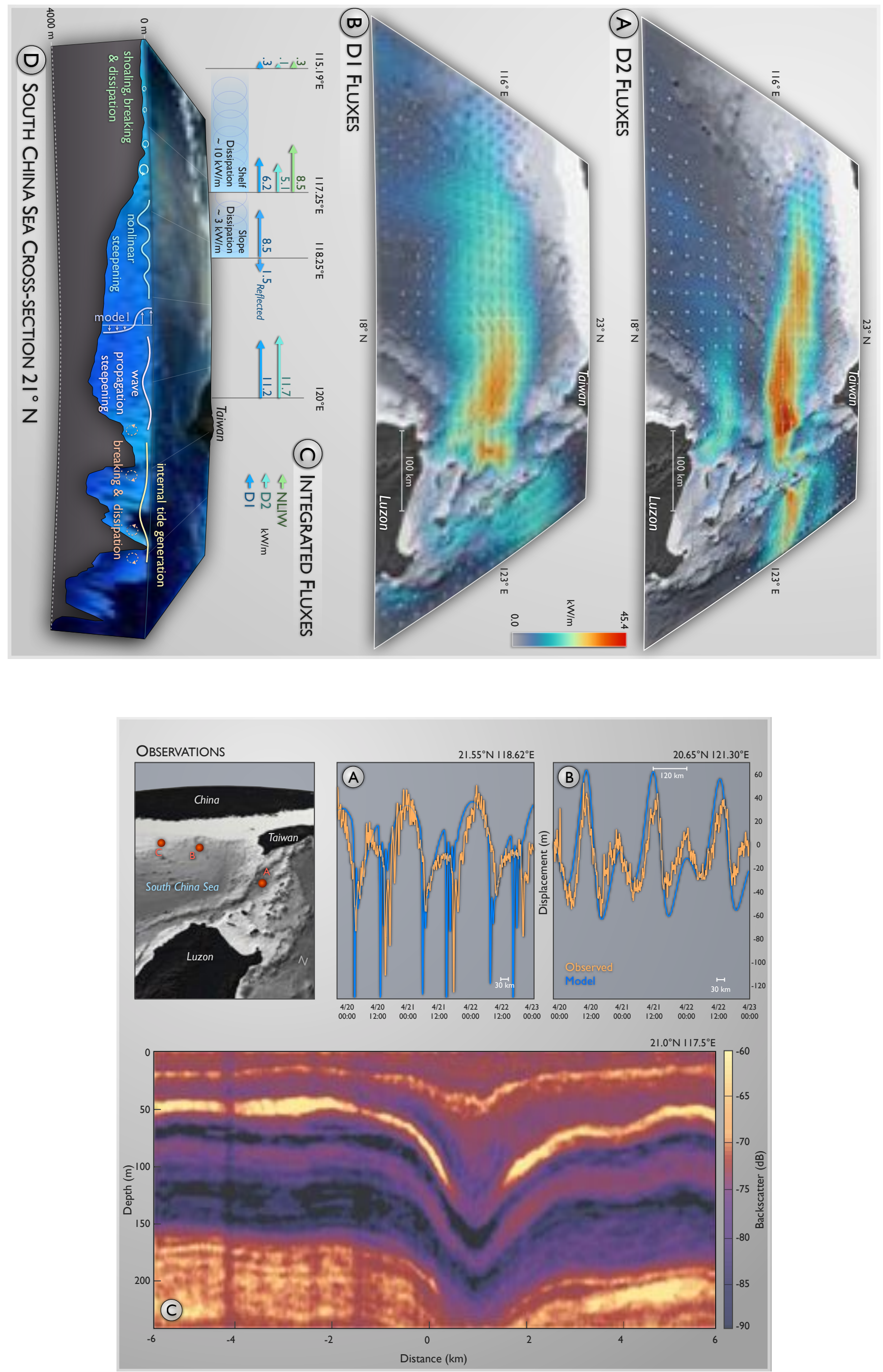